\title{
ANALISA DAN PERANCANGAN SISTEM INFORMASI PASIEN RAWAT INAP (STUDI KASUS : RUMAH BERSALIN AZIMAR ANAS PADANG)
}

\author{
Yonky Pernando*, Eka Lia Febrianti, Andhika \\ Teknik Informatika, Teknik Perangkat Lunak, Universitas Universal \\ email: yonkypernando@uvers.ac.id*
}

\begin{abstract}
In the era of globalization, information systems are now increasingly developing and are very important and main things in helping the process of corporate performance, in the near future that will make competition in the performance process will be more updated and faster. Because of that the use of information technology and the design of making application programs using Visual Basic 6.0 as programing and MySQL as its database, regarding the analysis and design of information systems for inpatients in anal azimar maternity homes. Problems - problems faced by this company, namely the problem of data redundancy in inputting data, and not presented properly and lead to difficulties when manipulating, changing, and deleting data. In the end the author hopes that with the creation of a new information system, it can help the input process more easily, and quickly.
\end{abstract}

Keywords: Technology, Information, PHP Programming Language, MySQL and Patient

\begin{abstract}
Abstrak: Di era globalisasi sekarang semakin berkembang nya sistem informasi serta merupakan hal yang sangat penting dan utama dalam membantu proses kinerja perusahaan, dalam waktu dekat yang akan membuat persaingan dalam proses kinerja akan semakin update dan cepat . Karena itu pemakaian teknologi informasi dan rancangan pembuatan program aplikasi dengan menggunakan Visual Basic 6.0 sebagai programing dan MySQL sebagai Databasenya, mengenai analisa dan perancangan sistem informasi pasien rawat inap di rumah bersalin azimar anas. Masalah - masalah yang dihadapi perusahaan ini yaitu masalah redundansi data dalam menginput data,dan tidak tersaji secara baik dan mengakibatkan kesulitan saat memanipulasi, mengubah, dan menghapus data. Pada akhirnya penulis berharap dengan dibuatnya sistem informasi yang baru, dapat membantu proses input dengan lebih mudah, dan cepat.
\end{abstract}

Kata kunci : Teknologi, Informasi, Bahasa Pemograman Visual Basic 6.0, MySQL dan Pasien 
DOI: https://doi.org/10.33330/jurteksi.v5i2.358

Available online at http://jurnal.stmikroyal.ac.id/index.php/jurteksi

\section{PENDAHULUAN}

Di era globalisasi sekarang semakin berkembang nya sistem informasi serta merupakan hal yang sangat penting dan utama dalam membantu proses kinerja perusahaan, dalam waktu dekat yang akan membuat persaingan dalam proses kinerja akan semakin update dan cepat . Karena itu pemakaian teknologi informasi dan rancangan pembuatan program aplikasi dengan menggunakan Visual Basic 6.0 sebagai Program dan MySQL sebagai Databasenya, mengenai analisa dan perancangan sistem informasi pasien rawat inap di rumah bersalin azimar anas. Masalah-masalah yang dihadapi perusahaan ini yaitu masalah redundansi data dalam menginput data,dan tidak tersaji secara baik dan mengakibatkan kesulitan saat memanipulasi, mengubah, dan menghapus data. Pada akhirnya penulis berharap dengan dibuatnya sistem informasi yang baru, dapat membantu proses input dengan lebih mudah, dan cepat.

Dalam rangka untuk lebih meningkatkan pelayanan kesehatan terhadap masyarakat, maka suatu perusahaan atau instansi yang bergerak dibidang kesehatan harus meningkatkan kemampuan dalam mengelola data pasien serta mampu memberikan informasi tentang pasien rawat inap di rumah bersalin azimar anas anduring padang yang bersangkutan

Untuk meningkatkan kemampuan pelayanan yang cepat, praktis, dan memuaskan kepada masyarakat, maka suatu perusahaan atau instansi memerlukan suatu alat yang dapat membantu suatu perusahaan atau instansi tersebut dalam pengolahan data. Komputer merupakan sebuah alat elektronik yang dapat membantu manusia dalam melakukan suatu pekerjaan tertentu dengan menggunakan program-program tertentu.

\section{METODE}

Untuk mencapai keakuratan dan ketelitian data serta informasi dalam penelitian ini maka pengumpulan data dilakukan dengan 3 cara:

1. Penelitan Lapangan (Field Research)

Dalam hal ini penulis melakukan penelitian langsung ke lapangan untuk mengumpulkan data secara langsung dengan cara menyajikan pertanyaan pertanyaan dan mengumpulkan formulir yang ada.

2. Penelitian Kepustakaan (Library Research)

Pengumpulan data juga dilakukan dengan membaca buku-buku literatur,diktat kuliah, buku-buku yang berkaitan dengan penelitian ini,kliping majalah, dan artikelartikel yang berasal dari internet.

3. Penelitian Laboratorium (Laboratory Research)

Adapun hardware dan software yang akan digunakan dalam penelitian laboratorium ini

\section{HASIL DAN PEMBAHASAN}

\section{Analisa Sistem}

Suatu sistem pada dasarnya merupakan suatu susunan teratur dari sekumpulan kegiatan-kegiatan yang saling berhubungan antara satu dengan yang lainnya, dan prosedur-prosedur yang dilaksanakan saling berkaitan sehingga memudahkan untuk melakukan kegiatan utama dari suatu organisasi[1].

Analisa sistem dilakukan untuk mengetahui masalah-masalah atau 
kekurangan-kekurangan yang ada pada sistem lama[2]. Hal ini dimaksudkan agar memudahkan dalam melakukan perancangan sistem yang baru sehingga kekurangan sistem yang lama dapat diperbaiki.

\section{Desain Sistem Aliran Sistem Informasi (ASI) Lama}

Di dalam mendisain suatu sistem baru, terlebih dahulu diketahui aliran sistem formasinya yaitu aliran sistem informasi yang sedang berjalan. Aliran sistem informasi ini melibatkan variabelvariabel atau bagian-bagian yang terorganisir berupa prosedur-prosedur atau langkah-langkah di dalam operasional bagian yang dibutuhkan[3].

Aliran sistem informasi yang sedang berjalan di RB. Azimar Anas khususnya pada sistem rawat inap adalah:

1. Pasien datang ke balai pengobatan R.B Azimar Anas lalu di catat data pasien untuk melakukan pemeriksaan selanjutnya.

2. Setelah data pasien di catat,Balai Pengobatan memberikan data tersebut ke Dokter untuk melakukan pemeriksaan kepada pasien.

3. Setelah dilakukan pemeriksaan terhadap pasien, maka akan diketahui apakah pasien harus dirawat inap atau hanya rawat jalan.

4. Jika pasien harus dirawat inap maka bagian balai pengobatan akan mengeluarkan surat rawat inap.

5. Surat rawat inap pasien yang telah terisi diserahkan ke bagian Administrasi.

6. Administrasi akan mencatat semua kebutuhan pasien mulai dari obat sampai yang lainnya.untuk mengetahui berapa pembayaran yang harus dibayar oleh pasien.

7. Kemudian kasir menghasilkan kuitansi pembayaran 2 rangkap,satu diberikan kepada pasien dan satu lagi digunakan untuk pembuatan laporan Perincian Biaya.

8. Kemudian laporan Perincian Biaya tersebut diserahkan kepada pimpinan.

Aliran sistem informasi lama pengolahan data pasien rawat inap pada rumah bersalin Azimar Anas sistem dapat dilihat pada gambar 1 .

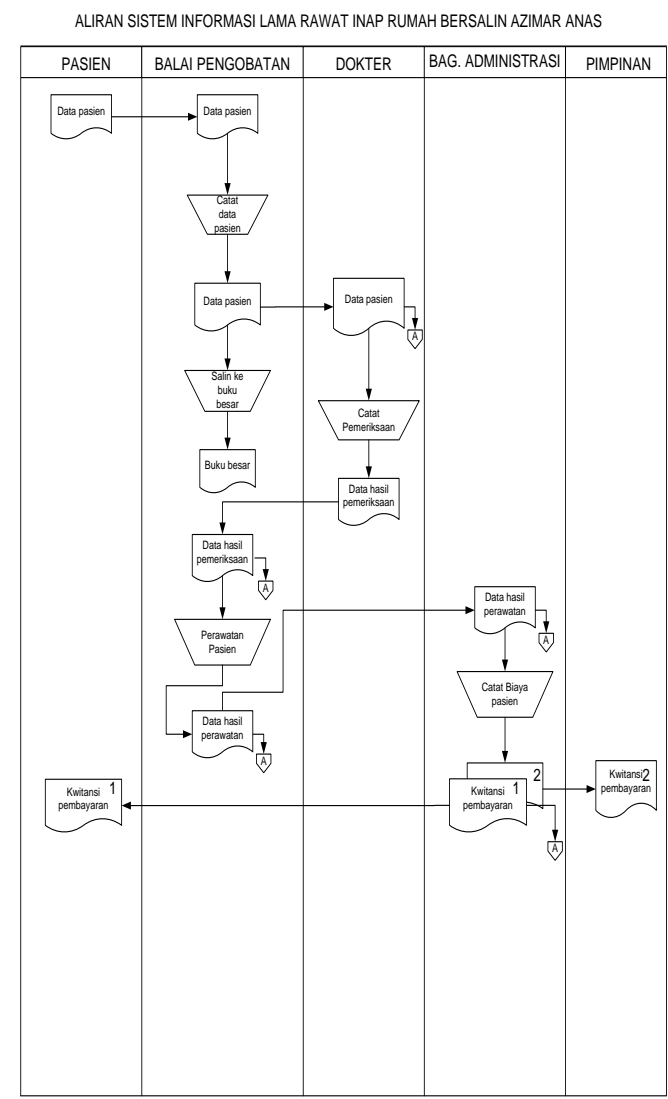

Gambar 1. Aliran Sistem Informasi (ASI) Lama

Desain Sistem Aliran Sistem Informasi (ASI) Baru

Untuk mendapatkan hasil yang maksimal dari perancangan sistem yang telah ada pada R.B Azimar Anas, maka dapat kita lihat pada sistem yang baru, dimana sistem yang digunakan adalah komputerisasi dan dengan database 
DOI: https://doi.org/10.33330/jurteksi.v5i2.358

Available online at http://jurnal.stmikroyal.ac.id/index.php/jurteksi

.Untuk lebih jelasnya komponen tersebut dapat dilihat pada gambar 2 berikut:

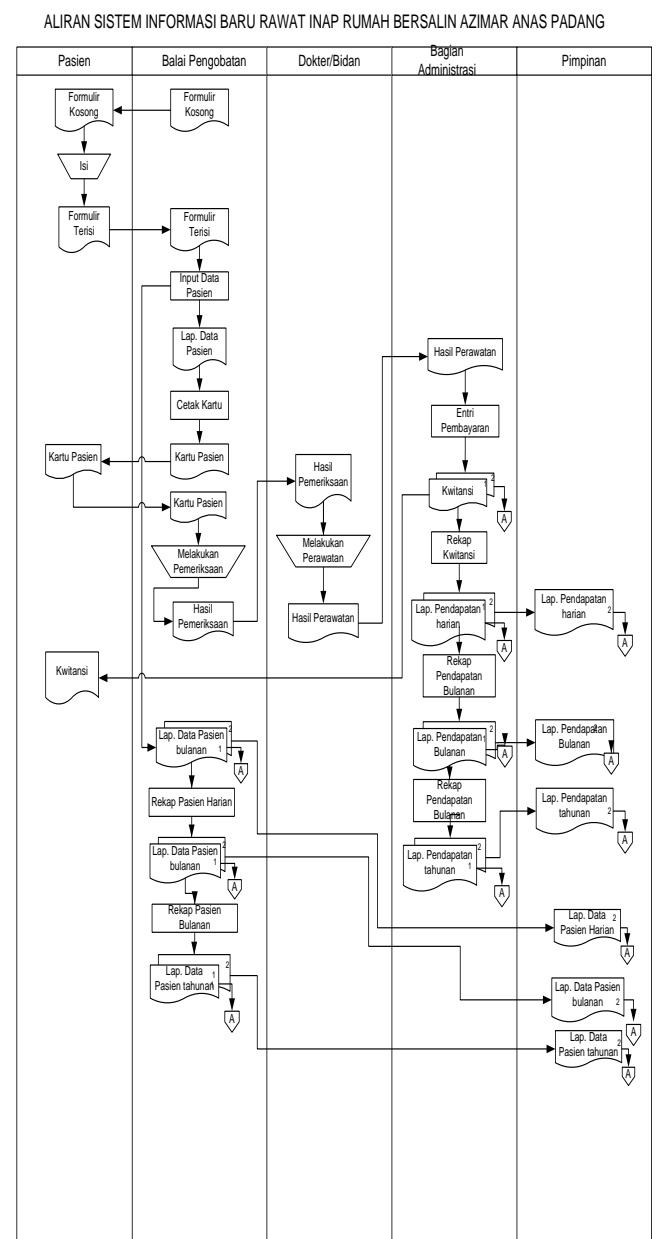

Gambar 2. Aliran Sistem Informasi (ASI) Baru

\section{Context Diagram}

Pada sub bab ini dijabarkan mengenai ruang lingkup analisa yang dilakukan sesuai dengan topik pembahasan[4]. Adapun penjabaran tersebut menggunakan context diagram, berikut ini gambar context diagram dimana terdiri atas sebuah lambang proses yang diberi tabel 0 (nol). Proses tersebut berinteraksi dengan beberapa entity Adapun bentuk dari Context Diagram yang dirancang dapat dilihat pada Gambar 3 berikut :
CONTEXT DIAGRAM RAWAT INAP RUMAH BERSALIN AZIMAR ANAS PADANG

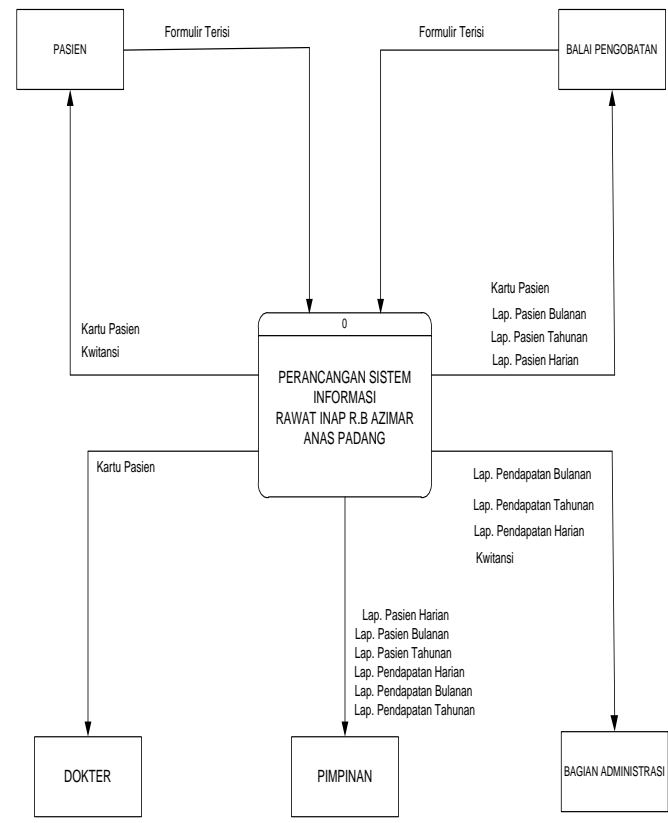

Gambar 3. Context Diagram

\section{Context Diagram}

Pada perancangan Data flow Diagram (DFD) level 1 haruslah berlandaskan dari Context Diagram yang telah dibuat sebelumnya. Data Flow Diagram level 1 yang telah dikembangkan berdasarkan Context Diagram yang ada dapat dilihat pada gambar 4 berikut

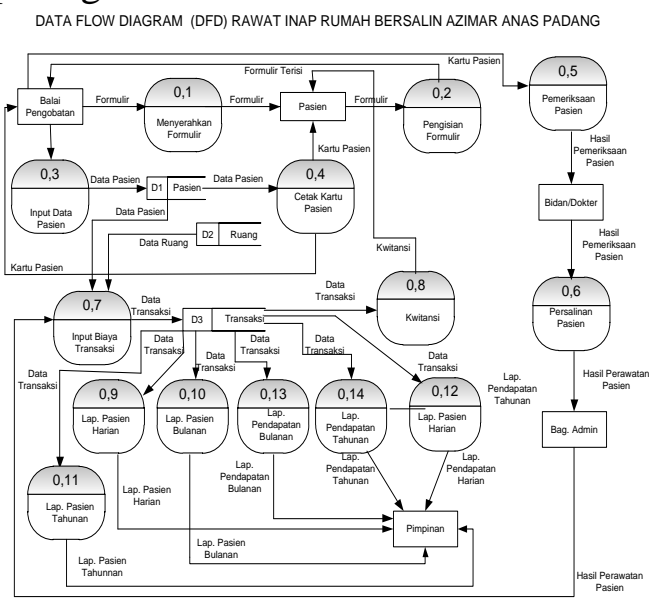

Gambar 4. Context Diagram Entity Relationship Diagram (ERD)

Entity Relationship Diagram (ERD) menggambarkan tentang hubungan antara 
DOI: https://doi.org/10.33330/jurteksi.v5i2.358

Available online at http://jurnal.stmikroyal.ac.id/index.php/jurteksi

suatu file dengan file yang lainnya, dengan menggunakan suatu penghubung yaitu relasi. Adapun bentuk dari Entity Relationship Diagram yang dirancang terdiri dari : Entity Pasien, Entity Ruang, Entity Perawatan, Entity Transaksi.

Untuk lebih jelasnya mengenai Entity Relationship Diagram (ERD) dapat dilihat pada gambar 5 berikut :

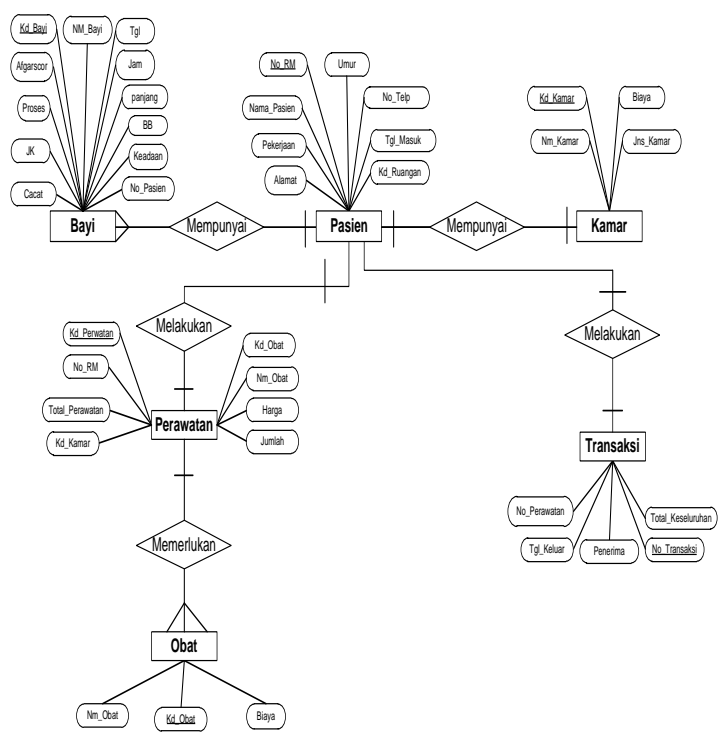

Gambar 5. Entity Relationship Diagram

\section{Halaman Form Menu Utama}

a. Halaman Menu Utama

Dari menu utama dipanggil sub-sub menu program yang lebih kecil karena menu utama berfungsi sebagai program pengumpulan dari sekian banyaknya menu, dimana dari menu utama dapat digunakan program-program yang ada agar dapat dijadikan satu program perancangan data. Berikut ini merupakan tampilan menu utama. Tampilan menu utama dapat dilihat pada gambar dibawah ini :

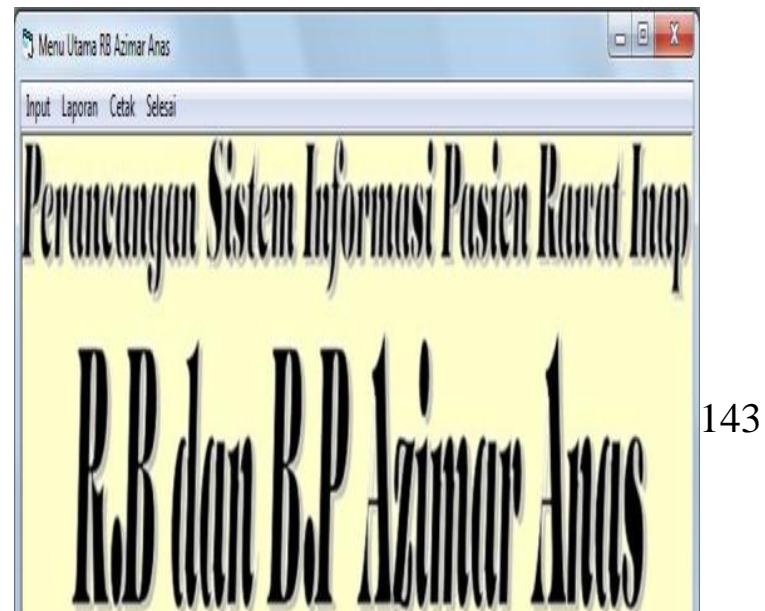

\section{Gambar 6. Menu Utama}

b. Halaman Entri Pasien

Pada Pogram entri data pasien ini akan direkam bila sudah benar dengan instruksi simpan, untuk menghapus record dengan mengklik tombol hapus, untuk mengedit record dengan mengklik tombol edit . Jika sudah tidak ada lagi yang akan dientrikan, maka bisa mengklik tombol keluar untuk kembali kemenu utama. Tampilan entry data Pasien.

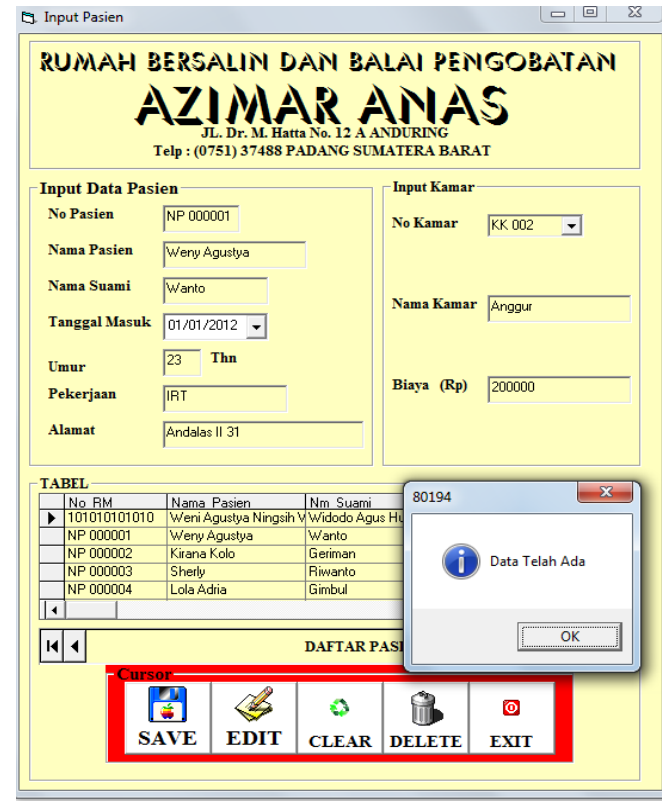

Gambar 7. Menu Entri Pasien

c. Halaman Entri Kamar

Pada program entri data ruang ini data akan akan direkam bila sudah benar 
dengan instruksi simpan, untuk menghapus record dengan mengklik tombol hapus, untuk mengedit record dengan mengklik tombol edit. Jika sudah tidak ada lagi yang akan dientrikan, maka bisa mengklik tombol keluar untuk kembali kemenu utama. Tampilan entri data kamar dapat dilihat pada gambar.

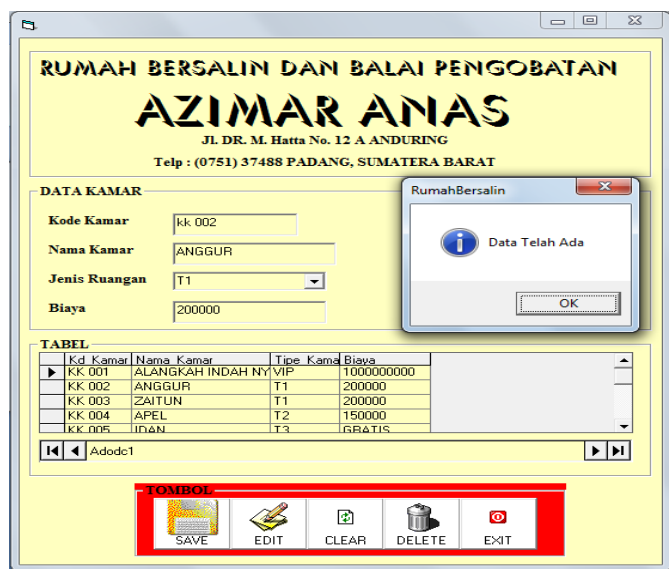

Gambar 8. Menu Entri Kamar

\section{d. Halaman Entri Transaksi}

Pada program entri transaksi ini data akan direkam bila sudah benar dengan instruksi simpan, untuk menghapus record dengan mengklik tombol hapus, untuk mengedit record dengan mengklik tombol edit. Jika sudah tidak ada lagi yang akan dientrikan, maka bisa mengklik tombol keluar untuk kembali kemenu utama. Tampilan entri kelahiran dapat dilihat pada gambar.

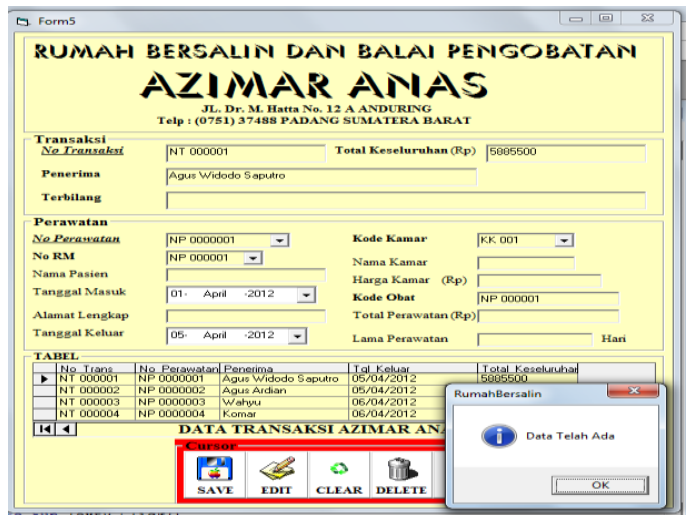

Gambar 9. Menu Entri Transaksi e. Halaman Entri Bayi

Pada program entri bayi ini data akan direkam bila sudah benar dengan instruksi simpan, untuk menghapus record dengan mengklik tombol hapus, untuk mengedit record dengan mengklik tombol edit. Jika sudah tidak ada lagi yang akan dientrikan, maka bisa mengklik tombol keluar untuk kembali kemenu utama. Tampilan entri Bayi dapat dilihat pada gambar.

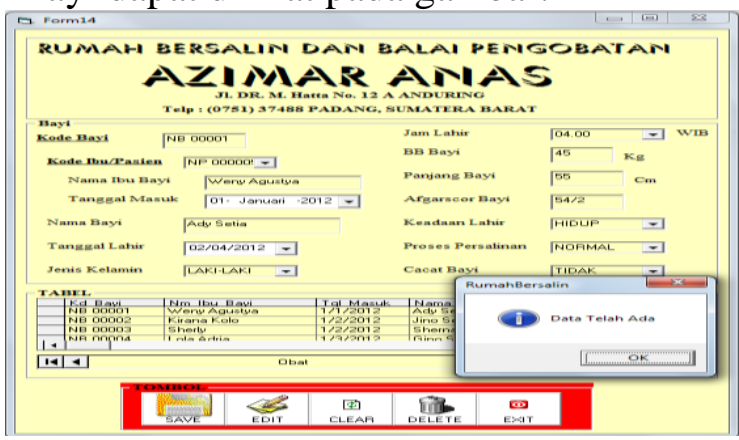

Gambar 10. Menu Entri Bayi

\section{f. Halaman Entri Perawatan}

Pada program entri perawatan ini data akan direkam bila sudah benar dengan instruksi simpan, untuk menghapus record dengan mengklik tombol hapus, untuk mengedit record dengan mengklik tombol edit. Jika sudah tidak ada lagi yang akan dientrikan, maka bisa mengklik tombol keluar untuk kembali kemenu utama. Tampilan entri perawatan dapat dilihat pada gambar.

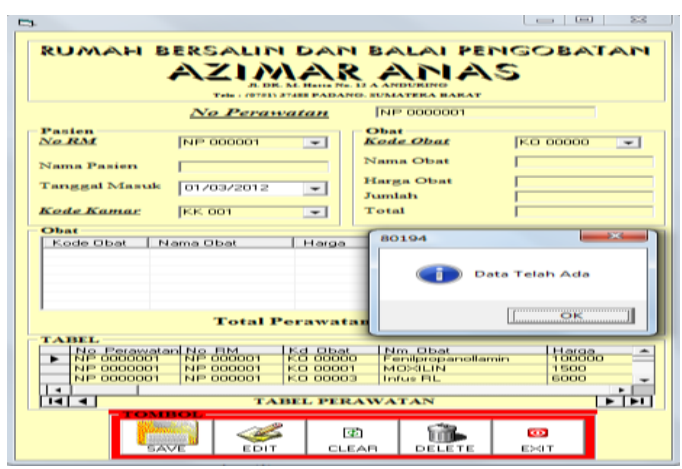

Gambar 11. Menu Entri Perawatan

g. Halaman Kartu Pasien

Pada Kartu Pasien menampilkan data pasien yang telah di inputkan sebelumnya. 
Untuk mencetak kartu pasien tersebut dapat dilakukan dengan menekan tombol cetak yang ada pada toolbar. Laporan daftar surat permohonan dapat dilihat pada gambar.

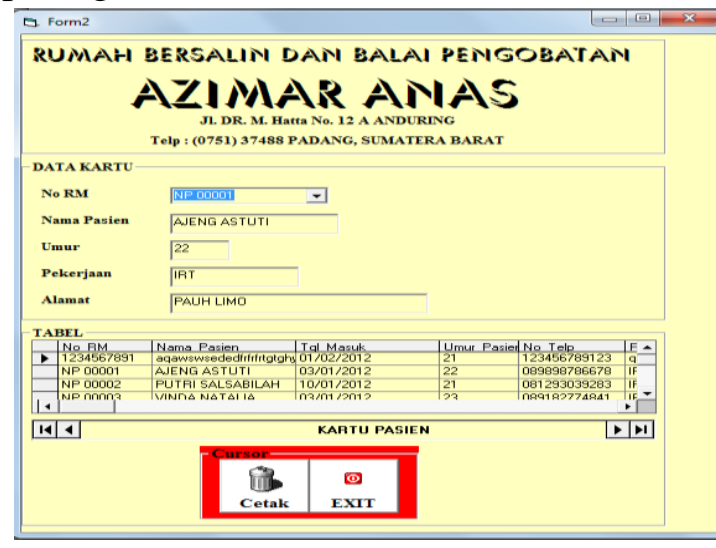

Gambar 12. Menu Entri Kartu Pasien

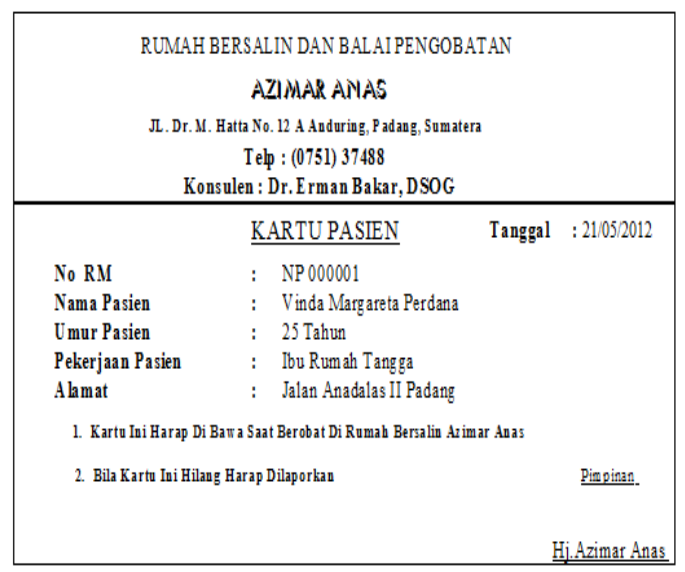

Gambar 13. Hasil Cetak Kartu Pasien

h. Halaman Kwitansi Pasien

Pada kwitansi ini menampilkan jumlah biaya pasien selama di rawat di rumah bersalin. Untuk mencetak kwitansi dapat dilakukan dengan menekan tombol cetak yang ada pada toolbar. Contoh bentuk kwitansi dapat dilihat pada gambar.

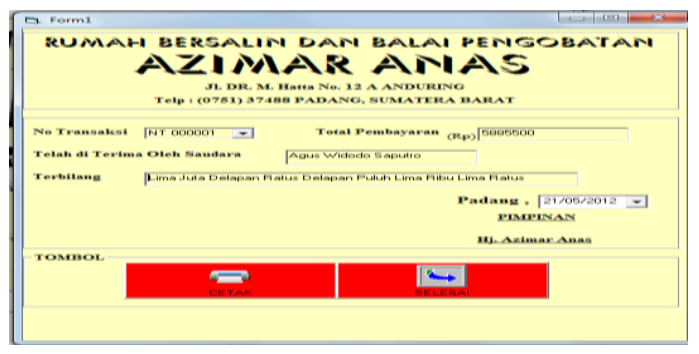

Gambar 14. Menu Entri Kwitansi

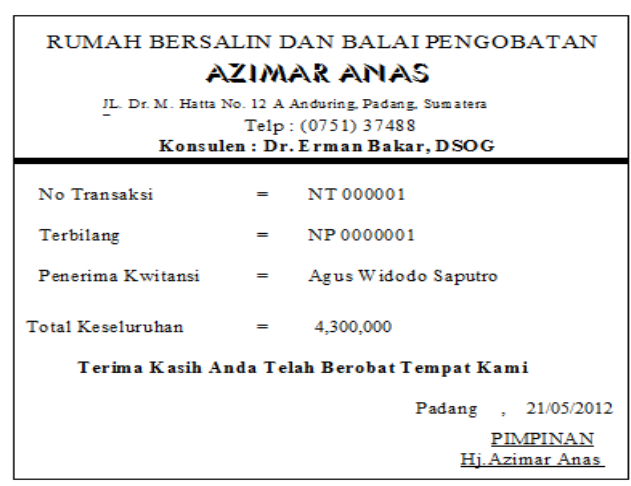

Gambar 15. Hasil Cetak Kwitansi SIMPULAN

Dari analisa yang dilakukan terhadap Rumah Bersalin Azimar Anas, maka penulis mengambil beberapa kesimpulan, dengan adanya perancangan sistem informasi data pasien rawat inap ini, maka dapat lebih mudah dalam melakukan proses pengentrian dan pembuatan laporan, serta mudah dalam melakukan proses pencarian, peninjauan dan pengalokasian data pada database sehingga dapat di olah dengan cepat, akurat dan relevan.

\section{DAFTAR PUSTAKA}

[1] Hartono Jogianto, MBA, Ph. D, 2005, "Analisis dan Desain Sistem Informasi", Andi, Yogyakarta

[2] Jogianto HM. (2003). "Pengantar Database" Ditemukan tanggal 11 Januari 2008. dari http://wwww.sqlcourse.com.

[3] Kadir Abdul, 2003, "Pengenalan Sistem Informasi”, Ansi, Yogyakarta.

[4] Suryadi, Agus, Mahardika Abdi Prawira Tanjung, and Eka Lia 
DOI: https://doi.org/10.33330/jurteksi.v5i2.358

Available online at http://jurnal.stmikroyal.ac.id/index.php/jurteksi

Febrianti. "Analisis Dan

Perancangan Webbase Dan Wap

Ticket Center Reservation Pada Po.

Npm Dengan Metode Prosedur

Multi User." JURTEKSI 5.1 (2018):

$37-42$. 